\title{
Density and Susceptibility Status of Malaria Vectors of Chilkuti Area, Bastar, Chhattisgarh
}

\author{
$\underline{\text { Anju Viswan K', TP Devanagan }}{ }^{2}, \underline{\text { Radhey Lal Korram }}^{3}, \underline{\text { Sandip S Jogdand }}^{4}, \underline{\text { SK Jain }}^{5}, \underline{\text { SK Singh }}^{6}$
}

1,2,3,4 National Centre for Disease Control, Jagdalpur, Chhattisgarh, India.

${ }^{5,6}$ National Centre for Disease Control, Delhi, India.

DOI: https://doi.org/10.24321/0019.5138.201931

I $\quad \mathbf{N} \quad \mathbf{F} \quad \mathbf{O}$

\section{Corresponding Author:}

Anju Viswan K, National Centre for Disease

Control, Jagdalpur, Chhattisgarh, India.

E-mail Id:

anjuviswan@gmail.com

Orcid Id:

https://orcid.org/0000-0001-7926-5826

How to cite this article:

Anju Viswan K, Devanagan TP, Korram RL, Jogdand SS, Jain SK, Singh SK. Density and Susceptibility Status of Malaria Vectors of Chilkuti Area, Bastar, Chhattisgarh. J Commun Dis 2019; 51(4): 10-15.

Date of Submission: 2019-12-15

Date of Acceptance: 2020-01-04
$\begin{array}{llllllll}\mathbf{A} & \mathbf{B} & \mathbf{S} & \mathbf{T} & \mathbf{R} & \mathbf{A} & \mathbf{C} & \mathbf{T}\end{array}$

Introduction: The study was carried out in Chilkuti, a village $22 \mathrm{~km}$ from Jagdalpur in Bastar Division of Chhattisgarh State, India. The malaria incidence of this area was declined with distribution of insecticide treated LLINs to the villagers. The present study aims to find out the vector density and insecticide susceptibility status of vector mosquitoes of the area.

Methods: Adult mosquito collections were done from both cattle shed and human dwelling by hand catch method and per man hour density calculated to compare the density of mosquitoes. The susceptibility/ resistance status against the conventional insecticides as per NVBDCP guidelines was evaluated by WHO susceptibility kit. Correlation of climatic factors and vector density was evaluated by SPSS version 20. Knock-down time (KDT50 and KDT 99) along with slope and 95\% confidence interval $(\mathrm{Cl})$ was determined using Ldp Line computer programme.

Result: The vector density was evaluated regularly and found to be the density of Anopheles culicifacies Giles, the major vector of malaria in the area getting reduced and in the meantime the density of Anopheles subpictus Grassi, is increasing. Though the An. culicifacies density found reducing and the cases of malaria were reported from the area indicating the possibility of another vector may be playing the role in parasitic transmission in the area. As per the previous study from NCDC Jagdalpur, the presence of sporozoites was confirmed in An. subpictus and anthropophilic index indicated the chance of its vectorial capacity in Jagdalpur area, Bastar division So the present study focused on both these mosquitoes. The susceptibility tests shown that there is variation in the susceptibility/resistant status of both the mosquitoes against the different classes of insecticides.

Conclusion: The results of the study exhibit the need of further exploratory research studies confirming the vectorial capacity of $A n$. subpictus and alternate measures to control malaria transmission.

Keywords: Malaria, Anopheles culicifacies, Anopheles subpictus, Insecticide Resistance 


\section{Introduction}

Malaria is a major health problem in Chhattisgarh and a main cause of mortality and morbidity among the peoples of tribal dominated districts. This disease is caused by female anopheles mosquito transmitting Plasmodium parasites. In India, Anopheles culicifacies, An. stephensi, An. fluviatilis, An. minimus, An. dirus and An. sundaicus are six primary and An. varuna, An. annularis, An. philippinensis and $A n$. jeyporiensis are four secondary vectors ofmalaria. ${ }^{1}$ In addition to these, An. subpictus has also been reported as a potential malariavector. ${ }^{2}$ Occurrence of oocyst and sporozoites in An. subpictus in India was first reported by Russel et al., in 1939 from Tamil Nadu. ${ }^{3}$ As per the reports of Kulkarni, sporozoites were detected in the salivary gland of An. subpictus from Bastar District in 1982. ${ }^{4}$

For the control of vector mosquitoes, indoor residual spraying with DDT was used initially, but gradually $A n$. Culicifacies has developed resistance against DDT and now An. culicifacies is resistant to DDT in almost all parts of the country. ${ }^{5}$ An. subpictus also had shown resistance towards DDT. ${ }^{6}$ In 1969, malathion was introduced in mosquito control programme in DDT resistant areas. ${ }^{7}$ An. culicifacies and An. Subpictus has developed varying degree of resistance to malathion in the country. ${ }^{8-11}$ In 1990's synthetic pyrethroids like deltamethrin were introduced in national vector borne disease control programme (NVBDCP). Mittal et al., ${ }^{12}$ Singh et $a .^{13}$ and Sharma et $a l .{ }^{8,14}$ reported reduced susceptibility to deltamethrin in An. culicifacies. The continuous and over usage of these synthetic pyrethroids leads to the development of resistance in Anophleles mosquitoes ${ }^{15}$ then also, synthetic pyrethroids are still used in various parts of the country as an effective insecticide for mosquito control. ${ }^{16,17}$

In the present study, Chilkuti, the study area has the number of malaria cases declined as compared with previous years after the implementation of vector control methods like IRS and LLINs. The Chhattisgarh Government supplied nets were treated with deltamethrin and NCDC supplied LLINs were with alphacypermethrin with free of cost and ratio of one bed net per two persons. The real effectiveness depends upon the proper usage. Usage of bed nets has strong relation with seasonality, mainly using in rainy season. Field studies indicate that bed nets were not used by all family members and the nets were alternatively used as fishing nets, used for covering crops, to protect saplings etc. The efficacy of IRS depends upon social factors like cooperation of the residents; most of the villagers won't allow doing IRS in all the rooms. So, the incomplete IRS with right formulation and insecticide will also lead to selection of resistance mosquitoes in the field. Insecticide spraying for mosquito control and LLINs were common methods for vector control regularly; however, resistance levels in malaria vectors has not been monitored for any insecticides in the area. So, the present study aims to find out the insecticide susceptibility/ resistance status of An. culicifacies, (major vector) and An. subpictus, (most abundant Anopheline mosquito) in the Chilkuti area.

\section{Methods}

The study was conducted from October 2017 to August 2019 in Chilkuti a small Village/ hamlet in Jagdalpur Tehsil in Bastar District of Chhattisgarh State, India. It comes under Kurandi Panchayath. It is located 22 KM towards South from District headquarters Jagdalpur. Gonds, Halwa, Bhadra and Sundi are the major tribes residing in this area. The main base of the economy of this area is agriculture and people depend on forest for wood, bamboo mahua, sal seeds and leaves. Both male and female works in agricultural field. Primarily they prefer natural medicines rather than allopathic medicines and treatment.

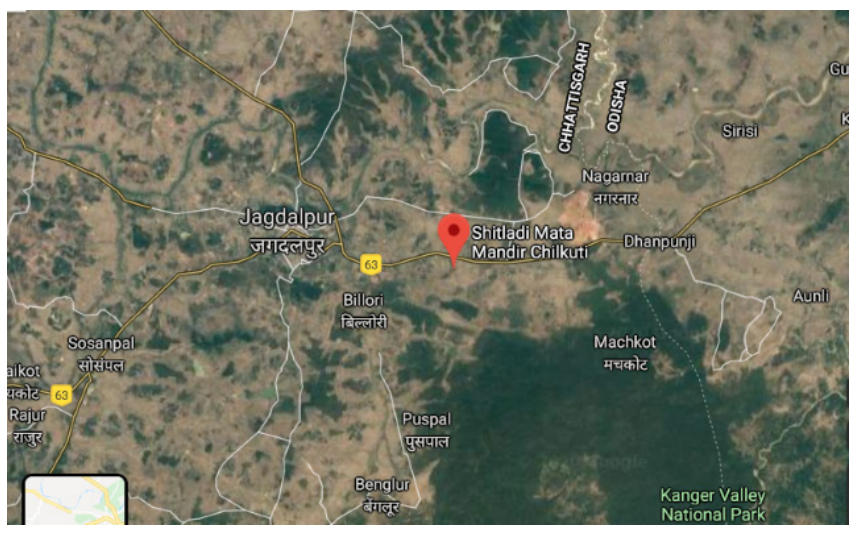

Figure I.Map of Chilkuti (Study Area)

Collection of Mosquitoes and Calculation of Vector Density

Adult mosquitoes were collected from cattle sheds using oral aspirator.

\section{Inclusion Criteria}

An.culicifacies and An.subpictus were sorted out from the collected mosquitoes and included in the study for susceptibility assay.

\section{Exclusion Criteria}

Other genus of mosquitoes and subspecies of Anopheline mosquitoes were excluded.

\section{Vector Density Calculated using the Formula}

Per man hour density=No. of mosquitoes collected/ No. of collectors $x$ time spent in search per hour.

Data on Climatic factors sought from the website of world weather online. Correlation of climatic factors and vector density was evaluated by SPPS version 20.

Insecticide susceptibility assay done using Alphacypermethrin (0.5\%), Deltamethrin (0.05\%), DDT (4\%), Malathion (5\%) 
and Bendiocarb $(0.1 \%)$ treated papers provided in WHO insecticide susceptibility evaluation test kits and protocol. ${ }^{18}$ The control tests were performed using pre-impregnated paper with silicone oil (Deltamethrin and Alphacypermethrin Control), risella oil (DDT control) and olive oil (malathion control) along with each set of insecticide bioassay. 20 mosquitoes were used in the test for 1 hour and cumulative knock-down time was recorded after an interval of 10 minutes up to 1 hour. Knock-down time (KDT50 and KDT99) along with slope and 95\% Confidence Interval (Cl) was determined using Ldp Line computer programme. After 1 hour the mosquitoes were transferred in to holding tube and $\%$ Mortality was recorded after 24 hours holding period. The mortality observed in the mosquito species was corrected using Abbott's formula. ${ }^{19}$

\section{Statistical Analysis}

SPSS version 20 and Ldp Line computer programme were used for the interpretation of data.

\section{Result and Discussion}

Figure 2, depicts the per man hour density of An. culicifacies and An. subpictus collected from the cattle sheds of Chilkuti area. The mosquito collection done on October-2017, January, April, July-2018 and April, July, August-2019. An. Culicifacies density was very less as compared with An. subpictus in all the time. In 2019 July and August, the density of both species seems to be very high. The rainfall rate was very high as compared with the previous years, and that may be a reason for the hike in vector density. In October 17, January \& April-2018, March \& April-2019, the PMHD of An. culicifacies was found to be zero. But An. subpictus collections were got in every catch.

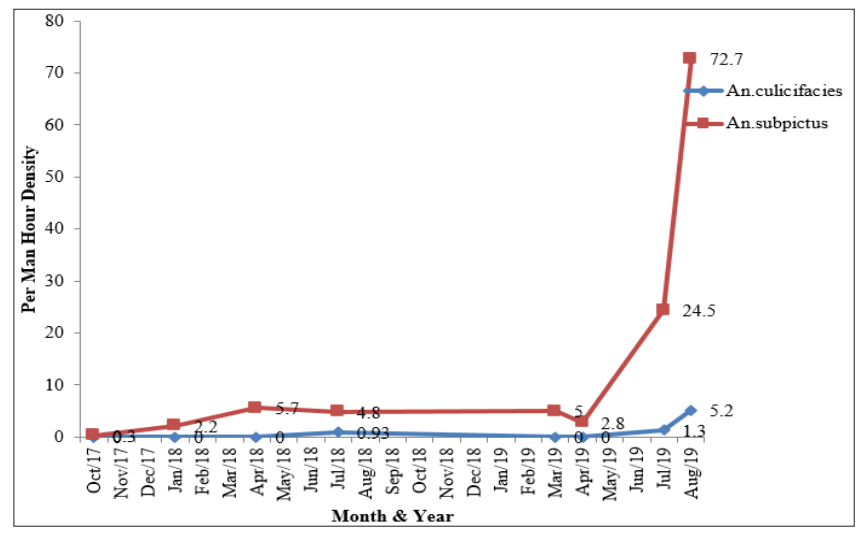

Figure 2.PMHD of An. culicifacies and An. subpictus

Figure 3 and 4, depicts climatic factors like temperature, humidity and rainfall in the Chilkuti area from January 2017 to October 2019 and the correlation of mosquito density with the climatic factors. Rainfall was high in the year 2019 as compared with previous years. In the present study mosquito density is significantly correlated with rainfall with $r$-value more than 0.8 . It is proved changes in climatic factors influence malaria directly by modifying the behaviour, geographical distribution and density of vectors. ${ }^{20}$ Limited studies on relationship between the climatic factors and malaria were carried out in malarial endemic areas Dehradun of Uttaranchal, ${ }^{21}$ Sonitpur ${ }^{22}$ and Kokrajhar of Assam ${ }^{23}$ and found to be the density and cases were related with climatic factors.

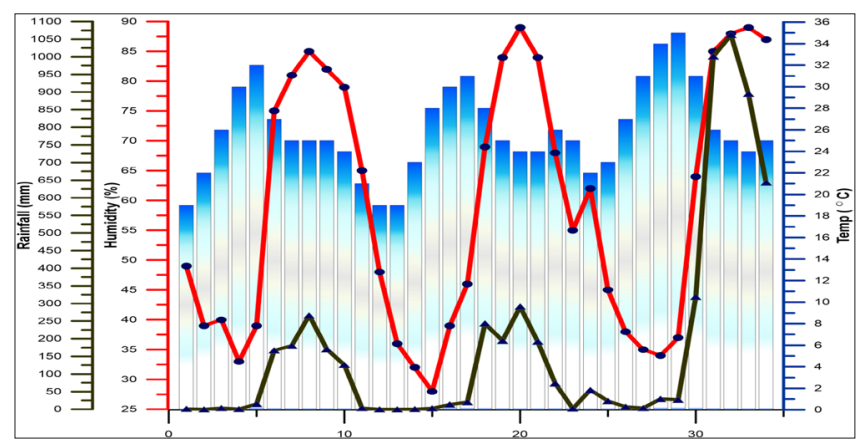

Figure 3.Climatic conditions of Chilkuti Area from January 2017 to October 2019

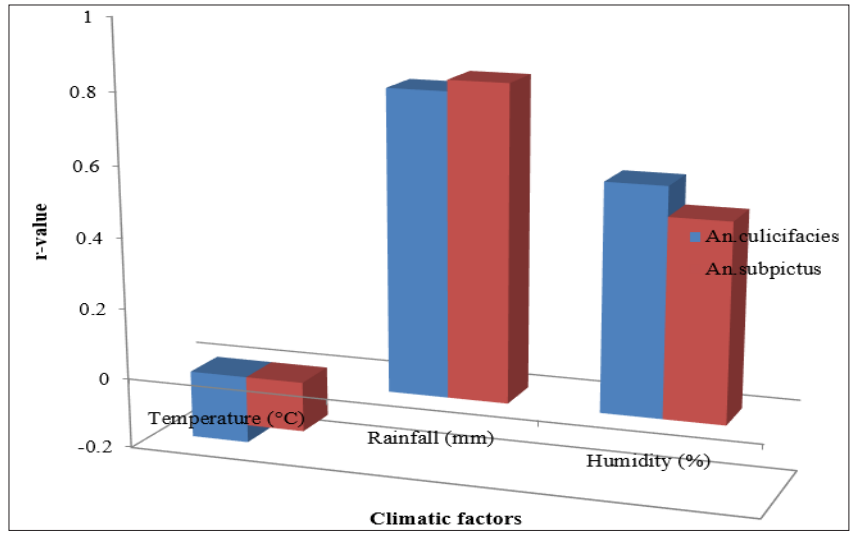

$r>0.8=$ highly correlated, $+r=$ positive linear relationship, $r=$ negative linear relationship

Figure 4.Correlation of mosquito density with temperature, rainfall and humidity

Table 1, show data regarding the knock down $\%$ in 1 hour, mortality \% after 24 hours and susceptibility/ resistance status of An. culicifacies and An. subpictus against DDT, bendiocarb, malathion, deltamethrin and alphacypermethrin. According to WHO guidelines, $98-100 \%$ mortality indicates susceptibility, $80-98 \%$ indicates the possibility of resistance that needs to be confirmed and $<80 \%$ indicates resistance. In the present study, An. subpictus had shown percentage mortality value less than $80 \%$ and proved its resistance towards all the conventionally used insecticides. The percentage mortality rate was very less in the test with DDT and its shows high resistance towards DDT. Higher levels of malathion resistance could be due to agricultural pesticides used for paddy pest control where An. subpictus breeds and it also used in vector control. ${ }^{23}$ This species has been reported to be resistant to DDT and dieldrin/ $\mathrm{HCH}$ in Gujarat. ${ }^{24}$ 
Table I.Knock-down time and susceptibility/ resistant status of An. culicifacies and An. subpictus in Chilkuti against Alphacypermethrin, Deltamethrin, Malathion, DDT and Bendiocarb

\begin{tabular}{|c|c|c|c|c|c|c|c|c|c|}
\hline $\begin{array}{l}\text { Mosquito } \\
\text { species }\end{array}$ & Insecticide & $\begin{array}{c}\% K D \\
1 \mathrm{~h}(\mathrm{~N})\end{array}$ & $\begin{array}{l}\text { KDT50 (95\% } \\
\text { Cl) }\end{array}$ & $\begin{array}{c}\text { KDT99 } \\
(95 \% \mathrm{Cl})\end{array}$ & Slope $\pm S D$ & $\begin{array}{l}x 2 \\
(p)\end{array}$ & $r$ & $\begin{array}{l}\% \mathrm{CM} \\
24 \mathrm{~h}\end{array}$ & $\begin{array}{l}\mathrm{S} / \mathrm{R} \\
\text { status }\end{array}$ \\
\hline \multirow{5}{*}{$\begin{array}{c}\text { An. } \\
\text { culicifacies }\end{array}$} & $\begin{array}{c}\text { Alpha } \\
\text { cypermethrin }\end{array}$ & $\begin{array}{l}87.5 \\
(40) \\
\end{array}$ & $\begin{array}{c}25.3 \\
(23.9-26.7) \\
\end{array}$ & $\begin{array}{c}144.0 \\
(124.8-170.9) \\
\end{array}$ & $3.1 \pm 0.2$ & $\begin{array}{c}4.0 \\
(0.9) \\
\end{array}$ & 1 & 87.5 & VR \\
\hline & Deltamethrin & $\begin{array}{c}85 \\
(40) \\
\end{array}$ & $\begin{array}{c}31.4 \\
(29.6-32.4) \\
\end{array}$ & $\begin{array}{c}148.2 \\
(130.7-170.1) \\
\end{array}$ & $3.4 \pm 0.2$ & $\begin{array}{c}0.3 \\
(1.0) \\
\end{array}$ & 1 & 85 & VR \\
\hline & Malathion & $\begin{array}{l}62.5 \\
(40)\end{array}$ & $\begin{array}{c}51.4 \\
(43.2-73.6)\end{array}$ & $\begin{array}{c}384.8 \\
(341.8-1583.2)\end{array}$ & $2.6 \pm 0.2$ & $\begin{array}{c}14.7 \\
(0.05)\end{array}$ & & 62.5 & $\mathrm{R}$ \\
\hline & Bendiocarb & $\begin{array}{c}50 \\
(40) \\
\end{array}$ & $\begin{array}{c}71.2 \\
(53.0-83.3) \\
\end{array}$ & $\begin{array}{c}484.7 \\
(441.7-883.1) \\
\end{array}$ & $2.7 \pm 0.2$ & $\begin{array}{c}11.5 \\
(0.05) \\
\end{array}$ & 1 & 50 & $\mathrm{R}$ \\
\hline & DDT & $\begin{array}{c}35 \\
(40) \\
\end{array}$ & $\begin{array}{c}160.2 \\
(100.2-421.3) \\
\end{array}$ & $\begin{array}{c}2831.6 \\
(1444.8-7437.6) \\
\end{array}$ & $1.0 \pm 0.2$ & $\begin{array}{c}4.1 \\
(0.28) \\
\end{array}$ & 1 & 35 & $\mathrm{R}$ \\
\hline \multirow{5}{*}{$\begin{array}{c}\text { An. } \\
\text { subpictus }\end{array}$} & $\begin{array}{c}\text { Alpha } \\
\text { cypermethrin }\end{array}$ & $\begin{array}{c}78.3 \\
(120) \\
\end{array}$ & $\begin{array}{c}32.2 \\
(24.9-40.9) \\
\end{array}$ & $\begin{array}{c}152.5 \\
(103.4-466.9) \\
\end{array}$ & $2.9 \pm 0.2$ & $\begin{array}{c}10.6 \\
(0.02) \\
\end{array}$ & 1 & 78.3 & $\mathrm{R}$ \\
\hline & Deltamethrin & $\begin{array}{c}75 \\
(120)\end{array}$ & $\begin{array}{c}37.7 \\
(35.4-40.3)\end{array}$ & $\begin{array}{c}170.8 \\
(139.6-222.6)\end{array}$ & $3.5 \pm 0.3$ & $\begin{array}{c}6.6 \\
(0.2)\end{array}$ & 1 & 75 & $\mathrm{R}$ \\
\hline & Malathion & $\begin{array}{c}65 \\
(120)\end{array}$ & $\begin{array}{c}48.2 \\
(44.0-75.8)\end{array}$ & $\begin{array}{c}380.8 \\
(336.6-1580.2) \\
\end{array}$ & $2.5 \pm 0.2$ & $\begin{array}{c}12.6 \\
(0.05) \\
\end{array}$ & 1 & 65 & $\mathrm{R}$ \\
\hline & Bendiocarb & $\begin{array}{c}55 \\
(100) \\
\end{array}$ & $\begin{array}{c}64.5 \\
(42.8-86.1) \\
\end{array}$ & $\begin{array}{c}416.7 \\
(299.6-542.2) \\
\end{array}$ & $3.4 \pm 0.2$ & $\begin{array}{c}1.8 \\
(0.8) \\
\end{array}$ & 1 & 55 & $\mathrm{R}$ \\
\hline & DDT & $\begin{array}{c}37 \\
(100)\end{array}$ & $\begin{array}{c}91.4 \\
(79.8-109.3) \\
\end{array}$ & $\begin{array}{c}1357.3 \\
(841.5-2592.5) \\
\end{array}$ & $2.0 \pm 0.2$ & $\begin{array}{c}3.1 \\
(0.5) \\
\end{array}$ & 1 & 37 & $\mathrm{R}$ \\
\hline \multicolumn{10}{|c|}{$\begin{array}{c}\text { \% KD-knock down \% in 1h; N-number exposed; KDT-knock-down time in minutes; Cl-confidence interval; SD- } \\
\text { standard deviation; r-correlation; Coefficient \% CM-corrected mortality after } 24 \mathrm{~h} \text {; S-Susceptible (mortality > 98\%); } \\
\text { R-Resistant (mortality <80\%) and VR-Tolerant (mortality 81-97\%). }\end{array}$} \\
\hline
\end{tabular}

An. culicifacies shown resistance towards DDT, malathion and bendiocarb, with percentage mortality values $35,62.5$ and $50 \%$ respectively. While using alphacypermethrin and deltamethrin the \% mortality values were 87.5 and $85 \%$ respectively, it indicates the possibility of development of resistance towards these insecticides. Further studies are needed for the confirmation of the status; hence the sample size was less as compared with An. subpictus. An. Culicifacies is resistant to DDT in almost all parts of the country ${ }^{25}$ and the resistance towards DDT, malathion and deltamethrin in Chhattisgarh. ${ }^{26}$ Synthetic pyrethroids are being used in public health programs to control multipleresistant vectors and tackle epidemic outbreaks. Also, this is the only group of insecticides currently used for bed-net impregnation for malaria control. In addition, commonly synthetic pyrethroids are used for vector control via mosquito coils, mats and liquid vaporizers. Currently, the national program has no alternative insecticide for effective vector control or for insecticide resistance management. ${ }^{17}$ In India, synthetic pyrethroids and organophosphate pesticides are currently being used, not only for vector control, but also in the agricultural sector, mainly for control of lepidopteron pests. The continuous and over usage of these synthetic pyrethroids leads to the development of resistance in Anophlelesmosquitoes. ${ }^{15}$

\section{Conclusion}

Variation in insecticide resistance mainly depends upon the class and frequency of insecticide use in the field. Excessive and unwanted usage of insecticides not only increases vector resistance, but also results in cross resistance to other insecticides and it affects the proper vector control measures. In the present study, An. culicifacies and An. subpictus had shown high resistance to DDT irrespective of its withdrawal from IRS and replaced with other insecticide spray. This could be due to increased genetic stability of DDT resistance gene as was observed in both species.

An. Subpictus had shown resistance towards all the insecticides used for the study. And that may be a reason for its high density in the study area. But in the case of An. culicifacies, the mortality rates indicate the chances of developing resistance towards pyrethroid insecticides 
and resistance towards all other classes of insecticides. It requires further confirmation because the sample size was less as compared with An. subpictus.

In conclusion, the present data indicated the chances of development of resistance to pyrethroids in An. Culicifacies and resistance to pyrethroids in An. subpictusis of great concern to Indian malaria control programme as it is in extensive use in public health programmes for IRS and for impregnation of bed nets. Since there are limited numbers of insecticides available for vector control, an approach focused on the rotational use of insecticides or a mosaic strategy can be adopted to delay development of resistance in malaria vectors. Effective resistance management mainly depends upon early detection of the status of resistance; therefore, there is a need of monitoring to assess insecticide susceptibility at regular intervals and necessary to formulate effective vector control strategies.

\section{Conflict of Interest: None}

\section{References}

1. Dash AP, Valecha N, Anvikar AR, Kumar A. Malaria in India: challenges and opportunities. J Biosci 2008; 33(4): 583-592. Available from: https://www.ias.ac.in/article/ fulltext/jbsc/033/04/0583-0592 [PubMed/ Google Scholar].

2. Chandra G, Bhattacharjee I, Chatterjee S. A review on Anopheles subpictus Grassi - A biological vector. Acta Trop 2010; 115(1-2): 142-154. Available from: https://www.sciencedirect.com/science/article/abs/ pii/S0001706X10000343?via\%3Dihub [PubMed/ Google Scholar].

3. Russel PF, Rao TR, Jacob VP. Anopheles subpictus Grassi, 1889 and Anopheles vagus Donitz, 1902 found naturally infected with Plasmodia in South Eastern India. J Malar Inst India 1939; 2(1): 95-99. Available from: https:// www.cabdirect.org/cabdirect/abstract/19392901679 [Google Scholar].

4. Kulkarni SM. Detection of sporozoites in Anopheles subpictus in Bastar District, Madhya Pradesh. Indian J Malar. 1983; 20: 159-160. [Google Scholar].

5. Mittal PK, Wijeyaratne P, Pandey S. Status of insecticide resistance of Malaria, Kala-azar and Japanese Encephalitis Vectors in Bangladesh, Bhutan, India and Nepal (BBIN). Available from: http//:ehpproj.org/pdf/ Activity report 129. EHP Project 26568/EXANEMDR.

6. Bansal SK, Singh KV. Insecticide susceptibility status of some Anophelines in district Bikaner, Rajasthan. Indian J Malar 1996; 33(1): 1-6. Available from: http:// europepmc.org/article/med/8690127 [PubMed/ Google Scholar].

7. Raghvendra K, Subbarao SK. Chemical insecticides in malaria vector control in India. ICMR Bulletin 2002; 32(10): 93-99. Available from: https://www.icmr.nic.in/ sites/default/files/icmr_bulletins/buoct02.pdf [Google Scholar].

8. Sharma SN, Shukla RP, Mittal PK, Adak T. Insecticide resistance in malaria vector Anopheles culicifacies in some tribal districts of Chhattisgarh, India. Curr Sci 2007; 92(9): 1280-1282. Available from: https://www. jstor.org/stable/24097897?seq=1 [Google Scholar/ ResearchGate/].

9. Bhatt RM, Sharma SN, Barik TK, Raghavendra K. Status of insecticide resistance in malaria vector, Anopheles culicifacies in Chhattisgarh state, India. J Vec Born Dis 2012; 49(1): 36-38. Available from: http://www. mrcindia.org/journal/issues/491036.pdf [PubMed/ Google Scholar].

10. Singh RK, Dhiman RC, Mittal PK, Das MK. Susceptibility of malaria vectors to insecticides in Gumla District, Jharkhand state, India. J Vector Borne Dis 2010; 47(2): 116-118. Available from: http://www.mrcindia.org/ journal/issues/472116.pdf [PubMed/ Google Scholar].

11. Shukla RP, Sharma SN, Raghvendra K, Subbarao SK. A note on the susceptibility status of Anopheles culicifacies and Anopheles fluviatilis to Malathion in Nainital and Udhamsingh Nagar districts, Uttarakhand. J Commun Dis 2006; 38(4): 369-372. [PubMed/ Google Scholar].

12. Mittal PK, Adak T, Singh OP, Raghavendra K, SK Subbarao. Reduced susceptibility to deltamethrin in Anopheles culicifacies sensual to, in Ramnathapuram district, Tamil Nadu - Selection of a pyrethroid-resistant strain. Curr Sci 2002; 82(2): 185-188. Available from: https://www. jstor.org/stable/24106111?seq=1 [Google Scholar].

13. Singh OP, Raghavendra K, Nanda N, Mittal PK, Subbarao SK. Pyrethroid resistance in Anopheles culicifacies in Surat district, Gujarat, West India. Curr Sci 2002; 82(5): 547-550. Available from: https://www.jstor.org/ stable/24105962?seq=1 [Google Scholar].

14. Sharma SK, Upadhyay AK, Haque MA, Singh OP, Adak T, Subbarao SK. Insecticide susceptibility status of malaria vectors in some hyper-endemic tribal districts of Orissa. Curr Sci 2004; 87(12): 1718-1726. Available from: https://www.jstor.org/stable/24109772?seq=1 [Google Scholar].

15. Tikar SN, Mendki MJ, Sharma AK, Sukumaran D, Veer $\mathrm{V}$, Prakash S et al. Resistance status of the malaria vector mosquitoes, Anophelesstephensi and Anopheles subpictus towards adulticides and larvicides in arid and semi-arid areas of India. J Insect Sci 2011; 11: 85. [PubMed/ Google Scholar].

16. Singh N, Chand SK, Bharti PK, Singh MP, Chand G, Mishra AK et al. Dynamics of Forest Malaria Transmission in Balaghat District, Madhya Pradesh, India. PLoS ONE 2013; 8(9): e73730. Available from: https:// journals.plos.org/plosone/article?id=10.1371/journal. 
pone.0073730 [Google Scholar]

17. Dash AP, Raghavendra K, Pillai MKK. Combating resistance to insecticides in malaria control: gains made in India. Public Health, Bayer Environ Sci 2006; 18: 30-37. [Google Scholar].

18. Test procedures for insecticide resistance monitoring in malaria vectors. Bio-efficacy and persistence of insecticides on treated surfaces. Report of the WHO informal consultation. World Health Organization, Geneva, 1998. WHO/CDC/MAL/ 98.12.

19. Abbott WS. A method of computing the effectiveness of insecticide. J Econ Entomol 1925; 18(2): 265-267. Available from: https://academic.oup.com/jee/articleabstract/18/2/265/785683? redirectedFrom=fulltext [Google Scholar].

20. Srimath-Tirumula-Peddinti RCPK, Neelapu NRR, Sidagam N. Association of climatic variability, vector population and malarial disease in district of Visakhapatnam, India: A modeling and prediction analysis. PLOS ONE 2015; 10(6): e0128377. Available from: https://journals.plos. org/plosone/article?id=10.1371/journal. pone.0128377 [PubMed/ Google Scholar].

21. Devi NP, Jauhari RK. Climatic variables and malaria incidence in Dehradun, Uttaranchal, India. Jour Vec Born Dis 2006; 43(1): 21-28. [PubMed/Google Scholar].

22. Nath DC, Mwchahary DD. Association between climatic variables and malaria incidence: a study in Kokrajhar district of Assam, India. Glob J H Sci 2013; 5(1): 90106. Available from: http://www.ccsenet.org/journal/ index.php/gjhs/article/view/21095 [PubMed/ Google Scholar].

23. Herath PR, Joshi GP. Pesticide selection pressure on Anopheles subpictus in Sri Lanka: comparison with two other Sri Lankan Anophelines. TransR Soc Trop Med and Hyg 1989; 83(4): 565-567. Available from: https://academic.oup.com/trstmh/article-abstract/8 3/4/565/1866026?redirectedFrom=fulltext [PubMed/ Google Scholar].

24. NMEP. Annual Report of the National Malaria Eradication Programme, Ministry Health and Family Welfare, Government of India. 1991.

25. Barik TK, Sahu B, Swain V. A review on An. culicifacies: from bionomics to control with special reference to Indian subcontinent. Acta Trop 2009; 109: 87-97. Available from: https://www.sciencedirect.com/science/article/ abs/pii/S0001706X08002635?via\%3Dihub [PubMed/ Google Scholar].

26. Bhatt RM, Sharma SN, Barik TK, Raghavendra K. Status of insecticide resistance in malaria vector, Anopheles culicifacies in Chhattisgarh state, India. J Vector Borne Dis 2012; 49(1): 36-38. Available from: http://www. mrcindia.org/journal/issues/491036.pdf [PubMed/ Google Scholar]. 